\title{
A. R. Crossman, D. Neary, Neuroanatomy. An illustrated colour text
}

\author{
Fourth edition, 2010, 200 pp ISBN 978-0-7020-3086-4 Churchill Livingstone Elsevier
}

\section{N. Tribolet}

Published online: 4 September 2010

(C) Springer-Verlag 2010

As the authors themselves state in their preface this book is mainly aimed at undergraduate medical students. It seems that as such it is widely known in the UK. I am not sure it is well known in continental Europe.

The anatomy of the peripheral and central nervous system is presented in a clear and didactic way. The illustrations are in colour and easy to study. When appropriate, actual anatomical and histological photographs, MRI pictures and angiograms are included.

Each chapter contains boxed pieces of text with summaries of typical clinical syndromes associated with the particular anatomy described (anatomo-clinical correlation).

N. Tribolet $(\bowtie)$

Neurochirurgie, HUG,

1211 Geneva, Switzerland

e-mail: Nicolas.DeTribolet@unige.ch
The book contains 17 chapters: 1. Introduction and overview of embryology, anatomy and physiopathology; 2. Cells of the nervous system; 3. Peripheral nervous system; 4. Autonomic nervous system; 5. Coverings of the central nervous system; 6. Ventricular system and cerebrospinal fluid; 7. blood supply of the central nervous system; 8. Spinal cord; 9. Brain stem; 10. Cranial nerves and cranial nerve nuclei; 11. Cerebellum; 12. Thalamus; 13. Cerebral hemisphere and cerebral cortex; 14. Corpus striatum; 15. Visual system; 16. Hypothalamus, limbic system and olfactory system; 17. problem solving, where the reader is asked to identify clinical syndromes.

Although trainees in neurosurgery and neurology will find it basic, this book should be in the library of neurosurgery and neurology units not only for medical students but also for junior doctors making a rotation. It will also be useful to prepare lectures for nurses.

Although I am not so junior anymore I enjoyed going through it myself. 